chen lassen, wurde die saure Flüssigkeit in einer kleinen Schale aus Platin mit reiner Chlorplatinlösung im Wasserbade abgedampft, der Rückstand mit ätherhaltigem Weingeist ausgezogen, das Ungelöste auf einem Filter gesammelt, ausgewaschen, getrocknet und gewogen. Ich erhielt auf diese Weise 0,006 Grammen Platinsalmiak, entsprechend 0,0008466 Grm. kohlens. Ammoniak. Da 36 Kubikfuss = 1,112 Kubikmetre bei $744^{\mathrm{mm}}, 97$ Barometerstand und $10^{\circ}, 5 \mathrm{C}$. Temperatur gleich sind 1,06 Kubikmetre bei $0^{\circ} 0 \mathrm{C}$. und $760^{\mathrm{mm}}$ B., diese aber 1377,014 Gran wiegen, so folgt hieraus, dass unter obigen Verbältnissen 1000000 Theile Luft 0,6148 Grammen, oder dass die Luft etwas mehr als $\frac{3}{5}$ Milliontheile kohlensaures Ammoniak enthalte.

Ich habe später nach anhaltend trocknem und warmem Wetter den Versuch wiederholı, und hierbei ziemlich dasselbe Resultat erhalten, was mir ganz unerwartet war. Die Witterungsverhältnisse haben sich seitdem nicht entschieden genug dem Trocknen oder Nassen zugewendet, um durch einen dritten Versuch zu einem entscheidendern Resultat zu gelangen. Wünschenswerth wäre es, dass recht Viele sich diesen Bestimmungen unterzögen, da dieselben sehr leicht ausfuhrbar sind.

\title{
Notiz über die Bereitung des Kali carbonicum e tartaro;
}

von

Ohme, Apotheker in Wolfenbüttel.

Bei der Darstellung des kohlensauren Kalis durch Verpuffung von einem Theile Salpeter mit zwei Theilen gereinigtem Weinstein wurde die erkaltete Masse, aus Mangel eines passenden eisernen Gefässes, in einem zinnernen Kessel mit destillirtem Wasser digerirt.

Nach 24 Stunden war der Kessel über der Flüssigkeit bedeutend corrodirt, und ergab sich bei der Untersuchung, dass die Flüssigkeit eine ziemlich bedeutende Menge von Cyankalium enthielt, welches durch Anziehung von Koh- 
lensäure zersetzt war, wobei sich durch die frei werdende Cyanwasserstoffsäure in statu nascenti eine bedeutende Menge von Cyanzinn oder Cyanzinnkalium gebildet und in der alkalischen Flüssigkeit gelöst hatte. Bei dem Abdampfen der Lauge zersetze sich das Cyankalium auf gewöhnliche Weise, was sich an der starken AmmoniakEntwickelung zeigte. Obige Bereitungsmethode möchte also wohl im Allgemeinen zu verwerfen sein*).

\section{Chemisch - pharmaceutische Notizen;}

\section{Von \\ H. K rämer in Firchen a. d. Sieg.}

1. Flüchtige Säuren des Cortex Viburni, Frangulae und der flores Sambuci.

Die in Berzelius' Jahresbericht 1845. p. 698 enthaltene Angabe Dumas', dass die Phocensäure nichts anderes als Valeriansäure sei, veranlasste mich, das Barytsalz. der aus der Rinde von Viburnum Opulus bereiteten flüchtigen Säure mit dem aus Baldrianwurzeln erhaltenen zu vergleichen. Beide, durch langsames Verdunsten unter der Glocke neben Schwefelsäure und Aetzkalk dargestellt, bildeten krystallinische Krusten von eigenthümlichem, der Buttersäure in Etwas ähnlichem Geruch und süsslichem Geschmack, welcher bei dem aus Viburnum erhaltenen Salze weniger intensiv war, was sich jedoch aus dem verschiedenen Alter der Salze und der dadurch bewirkten geringeren oder grösseren Ausscheidung von kohlensaurem Baryt erklären lässt. Mit verdünnter Schwefelsäure übergossen, entwickelten sie einen äusserst durchdringenden, zum Husten reizenden Geruch, ohne bemerkbare Verschiedenheit. Die Niederschläge, welche durch beide in den Auflösungen von salpetersaurem Silberoxyd, essigsaurem

*) Obige Notiz bestätigt lediglich die Erfahrung, welche ausführlich besprochen worden ist in den Ann. der Pharm. B. XXIV. p. 17 vom Jahre 1837. Vergl, Pharm. Centralbl. Jahrg. 1838. B. 1. p. 113. H, Wr. 